\title{
HEMS inter-facility transfer: a case-mix analysis
}

\author{
Damien Di Rocco ${ }^{1}$, Mathieu Pasquier ${ }^{2}$, Eric Albrecht ${ }^{3}$, Pierre-Nicolas Carron ${ }^{2}$ and Fabrice Dami ${ }^{2}$ (B)
}

\begin{abstract}
Background: Helicopter emergency medical services (HEMS) are popular rescue systems despite inconsistent evidence in the scientific literature to support their use for primary interventions, as well as for inter-facility transfer (IFT). There is little research about IFT by HEMS, hence questions remain about the appropriateness of this method of transport. The aim of this study was to describe a case-mix of operational and medical characteristics for IFT activity of a sole HEMS base, and identify indicators of over-triage.

Methods: This is a retrospective study on HEMS IFT over 36 months, from January 1st 2013 to December 31st 2015. Medical and operational data from the database of the Emergency Department of Lausanne University Hospital, which provides the emergency physicians for this helicopter base, were reviewed. It included distance and time of flight transport, type of care during flight, and estimated distance of transport if conducted by ground.

Results: There were 2194 HEMS missions including 979 IFT (44.6\%). Most transfers involved adults (> 17 years old; 799 patients, $81.6 \%)$. Forty patients (4.1\%) were classified as having benefitted from resuscitation or life-saving measures performed in flight, 615 (62.8\%) from emergency treatment and 324 (33.1\%) from simple clinical examination. The median distance by air between hospitals was $35.4 \mathrm{~km}$. The estimated median distance by road was $47.7 \mathrm{~km}$. The median duration time from origin to destination by air was $12 \mathrm{~min}$.

Conclusions: This case-mix of IFTs by HEMS presents a high severity. There are many signs in favour of over-triage. We propose indicators to help choosing whether HEMS is the most appropriate mean of transport to perform the transfer regarding patient condition, geography, and medical competences available aboard ground ambulances; this may reduce over-triage.
\end{abstract}

Keywords: Inter-facility transfer (IFT), Helicopter emergency medical services (HEMS), Case-mix, Over-triage

\section{Background}

Helicopter emergency medical services (HEMS) are popular rescue systems despite inconsistent evidence in the scientific literature to support their use for primary interventions, as well as for inter-facility transfer (IFT) [1-5]. For IFT, the main added values of the helicopter are speed of patient transport, and sometimes medical competences if not available in ground ambulances (GA). IFT can either upgrade the level of care (to a trauma centre or university hospital) or downgrade it (to make room in those trauma centres or university hospitals) [6].

\footnotetext{
* Correspondence: Fabrice.Dami@chuv.ch

${ }^{2}$ Emergency Department, Lausanne University Hospital (CHUV), Bugnon 46,

1011 Lausanne, Switzerland

Full list of author information is available at the end of the article
}

In contrast to direct transport from the scene of injury, there has been much less research about IFT by HEMS; hence, questions remain about the appropriateness of this method of transport. Furthermore, research on this topic has been mainly limited to specific types of disease (STEMI, stroke, spinal injury) and not on whole HEMS case-mixes [7, 8]. To the best of our knowledge, there is no generally accepted guideline that would help choose the most appropriate transport method for IFT, nor definition of over-triage when using the helicopter to perform those IFTs.

The aim of this study is to describe a single HEMS IFT case-mix and its severity, and identify over-triage through operational and medical indicators.

(c) The Author(s). 2018 Open Access This article is distributed under the terms of the Creative Commons Attribution 4.0 International License (http://creativecommons.org/licenses/by/4.0/), which permits unrestricted use, distribution, and reproduction in any medium, provided you give appropriate credit to the original author(s) and the source, provide a link to the Creative Commons license, and indicate if changes were made. The Creative Commons Public Domain Dedication waiver (http://creativecommons.org/publicdomain/zero/1.0/) applies to the data made available in this article, unless otherwise stated. 


\section{Methods}

\section{Setting.}

The State of Vaud (western Switzerland) has one trauma centre (Lausanne University Hospital), seven regional hospitals and many private clinics that are distributed equally over its territory. Most hospitals have a GA which they can use for transfers. All GAs are staffed with at least one paramedic. They use State protocols for autonomous intravenous access, cardiopulmonary resuscitation procedures, defibrillation and emergency medication administration. They are not allowed to manage upper airway disposals (intubation, laryngeal mask or tube) or continuous drug infusions (vasopressors, anaesthesia and sedation); these procedures require the presence of an emergency physician (EP). EPs are scarcely available to conduct IFT by GA as hospitals want to keep these scare resources within their emergency department. Therefore, HEMS which are staffed with their own EP and paramedic are regularly used to perform those transfers. Switzerland is very well covered for its area of 41,300 $\mathrm{km}^{2}\left(16,000 \mathrm{mile}^{2}\right)$, with 20 medically equipped helicopters from private companies during the daytime, and 8 during the night. In this State, requests for IFT by the helicopter are made by the hospital medical team in charge of the patient; there is no triage either from the HEMS companies or from dispatch centres regarding secondary transport.

\section{Study design.}

This was a retrospective study, carried out on data from January 1st 2013 to December 31st 2015 (36 months). All data were extracted from the database of the Emergency Department of the Lausanne University Hospital which staffs the EPs for this HEMS. Pre-hospital medical charts are completed by EPs and then checked by medical supervisors.

\section{Measurements and outcomes.}

Demographics (age and sex), diagnosis and operational data (distances, origin and destination, date, time of day and duration of flight) were collected. Patients who were 17 years of age and under were included in a paediatric subgroup. Outcome at $48 \mathrm{~h}$ (mortality, ICU or ward stay, discharge) was obtained from hospital charts. Diagnosis was grouped into nine clinical categories (heart and vessel disease, traumatology, neurology, pneumology, obstetrics, paediatrics, toxicology, psychiatry and miscellaneous). Patient care provided during transfer was classified into three care categories by EPs: simple clinical examination, emergency treatment and resuscitation or life-saving manoeuvres. Simple clinical examination consisted of simple monitoring of the patient during the flight. Emergency treatment consisted of administering any medication (continuously or not) including fluid resuscitation, even if it was started in the hospital, or to pursue ongoing ventilation. Resuscitation consisted of gestures and manoeuvres necessary to maintain the patient's life, such as cardiac massage, defibrillation or intubation. Specific treatments requiring the presence of an EP in this system (continuous drug infusion or airway management) were collected. Distances of journeys by road were calculated using Google $\mathrm{Maps}^{\circledR}$; major differences between flight and ground distances for the same IFT may reveal geographical constraints (e.g. mountains, water).

Data were integrated into an Excel $^{\odot}$ spreadsheet, and processed and analysed using Stata $\odot$ (Stata, Statistical Software 14.2, Stata Corporation, College Station, TX, USA).

\section{Results}

During the study period, there were 2194 HEMS missions including 982 IFT (44.8\%). Three patients were excluded as they died before take-off; the final group included 979 patients (Fig. 1) (Table 1). Most missions involved adults (> 17 years old) $(799 ; 81.6 \%)$. There were $772(78.8 \%)$ transfers from regional hospitals to a university hospital, 139 (14.2\%) from a university hospital to a regional hospital, 36 (3.7\%) from a regional hospital to another regional hospital and 32 (3.3\%) from a university hospital to another university hospital. Trauma patients represent 15 . $5 \%$ of the case-mix. Forty patients ( $4.1 \%$ of total) were classified as having benefitted from resuscitation or lifesaving measures performed in flight, 615 (62.8\%) from an emergency treatment and 324 (33.1\%) from a simple clinical examination. Table 2 lists the fate of all patients at $48 \mathrm{~h}$, regarding the type of care performed en route.

\section{Operational characteristics (Table 3 ).}

The median distance by air between hospitals was 35 . $4 \mathrm{~km}$. The median distance by road calculated using Google Maps $^{\oplus}$ was $47.7 \mathrm{~km}$. The overall duration from origin to destination by air was $12 \mathrm{~min}$.

There were 270 (27.6\%) transfers during weekends, and 361 (36.9\%) night transfers (7 pm-7 am).

\section{Discussion}

The decision to use HEMS is a sensitive topic, and there is no unambiguous evidence in favour or against its use for IFT in the literature; studies are carried out in different health policy settings and in different geographical environments; their results cannot be directly transposed to other EMS. Some studies have described factors (e.g. distance, geography) that influence the use of HEMS for IFT [9-11]; some demonstrated either a survival advantage $[1,12,13]$ or disadvantage $[2,11]$ for injured patients. Moreover, most of these studies take into account only one category of pathology and not the whole case-mix, as this study proposes [8, 9]. 


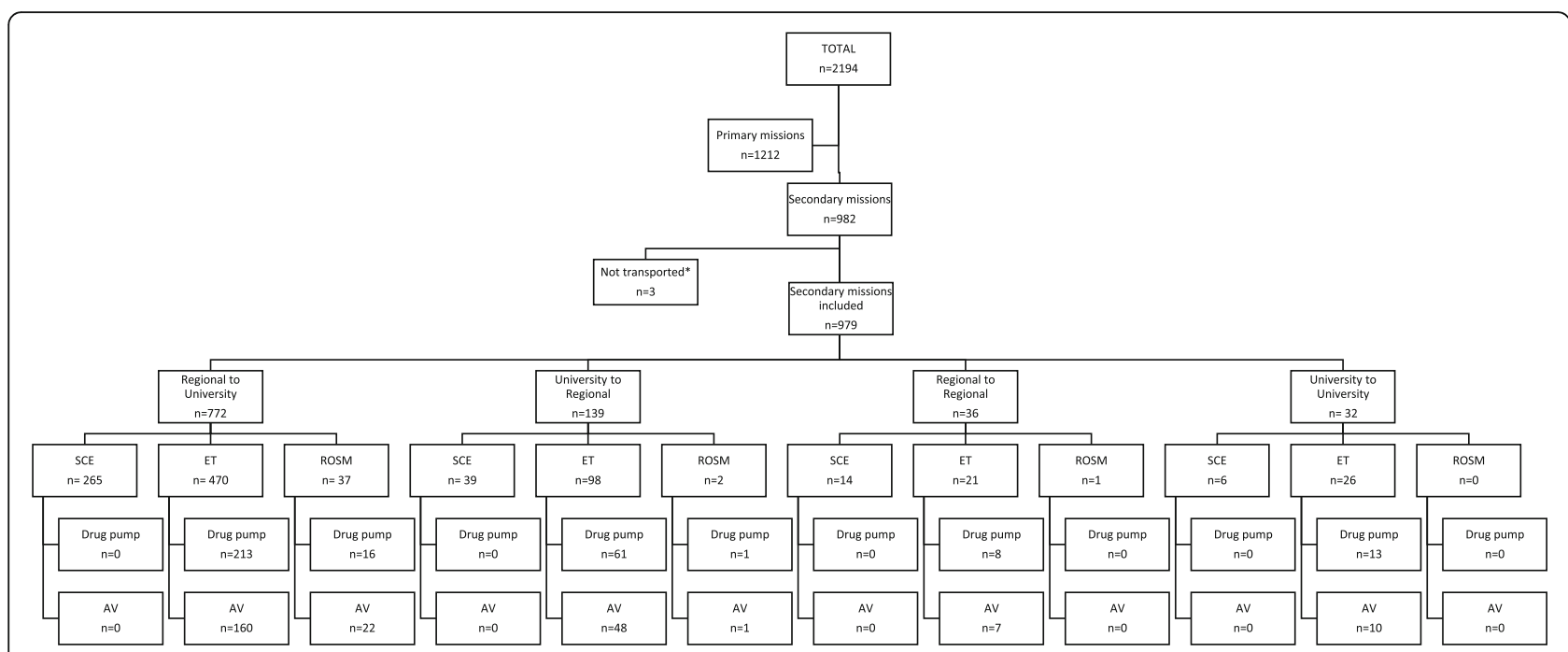

Fig. 1 Inter-facility transfer flowchart. SCE: simple clinical examination, ROSM: resuscitation or life-saving manoeuvres, ET: emergency treatment, AV: assisted ventilation (intubated/tracheotomised). ${ }^{*}$ not transported: died before take-off

The analysis of the case-mix, the first aim of the study, shows that $425(43.4 \%)$ patients were hospitalised in an ICU at $48 \mathrm{~h}$, which demonstrates the severity of this case-mix. There were few trauma cases in this case-mix, which could be explained by efficient sorting performed during on-scene missions, and a consequently low retransfer rate, as previously published in this HEMS [14]. Out of the 974 IFT, 772 (79\%) patients were transported from a regional hospital to a university hospital (upgrading the level of care).

The measure of over-triage, the second aim of the study, is complex and must take into account many different indicators. For example, upgrading the level of care or the severity conditions at $48 \mathrm{~h}$ mentioned above are not indicators that can justify the use of HEMS by themselves.

If speed is needed by the referral team, then distance by air and ground have to be taken into account. If they are very different (e.g. affected by mountains, water), the probability that HEMS may be faster is high. Regarding this issue, some have proposed using distances between hospitals or the expected duration of transfer to justify the use of HEMS $[15,16]$, but there is no consensus on a cut-off distance or time for which the helicopter should be used [5]. Kristiansen et al. showed an increase in the use of HEMS proportional to the distance to be covered, and a decrease in mortality for transfers by HEMS $\geq 100 \mathrm{~km}$ [15]. Another study recommends considering HEMS for distances $\geq 30 \mathrm{~km}$ by road for IFT [16]. If we transpose these values to our study, we note that $738(75 \%)$ missions were above the $30 \mathrm{~km}$ proposed limit, and $70(7 \%)$ above the $100 \mathrm{~km}$ limit. It should however be highlighted that although a helicopter can cover a greater distance than a GA in a given time, it is not always the fastest method of transfer [5]. Indeed, it takes longer to install a patient in a helicopter than in a GA. Take-off and landing procedures also take longer than starting an ambulance engine [17]. In this area, although hospital landing zones are open 24/24, they are often located on roof tops or at some distance from emergency departments. Finally, it should be mentioned that most hospitals have a GA service nearby, which may be at the patient's bedside somewhat quicker than HEMS. When looking for speed, the estimated global time of transfer from the call to the arrival at destination should be estimated by air versus ground.

In some EMS, GA medical competences are sometimes estimated to be insufficient to handle the patient and therefore HEMS is requested. This is the case in this study, as paramedics cannot handle intubation, mechanical ventilation or continuous drugs. When looking at the simple clinical examination group, the main possible added value of HEMS was speed of transport to exclude and/or treat a time-sensitive condition (i.e. STEMI, stroke, angiography, or neurosurgery) after having received all necessary treatment in the local hospital. When analysing in detail the diagnosis declared by EPs for this category, we can retrospectively hypothesise that some of them may not have needed HEMS as advanced medical competences were not required (head trauma with GCS 14, spine trauma without neurological deficit, pneumonia, intoxication, alcohol abuse). When looking ate the emergency treatment group, the vast majority did not benefit from ventilation or continuous drug treatment. The medical files were not retrospectively checked to determine whether continuous treatment could have 
Table 1 Patients' clinical characteristics including demographics, medical equipment according to the type of care provided, and clinical category $(n=979)$

\begin{tabular}{|c|c|}
\hline \multicolumn{2}{|l|}{ Demographic } \\
\hline \multicolumn{2}{|l|}{ All } \\
\hline n (\%) & $979(100)$ \\
\hline Gender male, n (\%) & $594(60.7)$ \\
\hline Age (mean \pm SD) (range) & $50.7 \pm 26.9(1-95)$ \\
\hline \multicolumn{2}{|l|}{ Adults } \\
\hline n (\%) & 799 (81.6) \\
\hline Gender male, n (\%) & $487(49.7)$ \\
\hline Age (mean \pm SD) (range) & $60.8 \pm 18.1(18-95)$ \\
\hline \multicolumn{2}{|l|}{ Paediatric patients } \\
\hline n (\%) & $180(18.4)$ \\
\hline Gender male, n (\%) & $107(10.9)$ \\
\hline Age (mean \pm SD) (range) & $6.1 \pm 5.1(1-17)$ \\
\hline \multicolumn{2}{|l|}{ Care category (=n) (\%) } \\
\hline Simple clinical examination & $324(33.1)$ \\
\hline Intubated before transfer & $0(0)$ \\
\hline Tracheotomized before transfer & $0(0)$ \\
\hline Infusion pumps & $0(0)$ \\
\hline Emergency treatment & $615(62.8)$ \\
\hline Intubated before transfer & $205(20.9)$ \\
\hline Tracheotomized before transfer & $20(2.0)$ \\
\hline Infusion pumps & $295(30.1)$ \\
\hline Resuscitation or life-saving measures & $40(4.1)$ \\
\hline Intubated before transfer & $23(2.3)$ \\
\hline Tracheotomized before transfer & $0(0)$ \\
\hline Infusion pumps & $17(1.7)$ \\
\hline \multicolumn{2}{|l|}{ Clinical category (= n) (\%) } \\
\hline Heart/vessel disease & $252(25.7)$ \\
\hline Myocardial infarct & $103(10.5)$ \\
\hline Chest pain & $38(3.9)$ \\
\hline Cardiac arrest & $28(2.9)$ \\
\hline Cardiac insufficiency & $17(1.7)$ \\
\hline Aortic abdominal aneurysm ruptured & $14(1.4)$ \\
\hline Other & $52(5.3)$ \\
\hline Traumatology & $152(15.5)$ \\
\hline Mild TBI (GCS 14-15) & $29(3)$ \\
\hline Blunt abdominal trauma & $24(2.5)$ \\
\hline Moderate TBI (GCS 9-13) & $13(1.3)$ \\
\hline Severe TBI (GCS 3-8) & $13(1.3)$ \\
\hline Other trauma & $73(7.5 \%)$ \\
\hline Neurology & $123(12.6)$ \\
\hline Stroke & $85(8.7)$ \\
\hline Status epilepticus & $16(1.6)$ \\
\hline
\end{tabular}

Table 1 Patients' clinical characteristics including demographics, medical equipment according to the type of care provided, and clinical category $(n=979)$ (Continued)

\begin{tabular}{ll}
\hline Demographic & \\
\hline Epilepsy & $14(1.4)$ \\
Other & $8(0.8)$ \\
Pneumology & $85(8.7)$ \\
Obstetrics & $58(5.9)$ \\
Paediatrics & $46(4.7)$ \\
Toxicology & $25(2.6)$ \\
Psychiatry & $3(0.3)$ \\
Miscellaneous & $235(24)$
\end{tabular}

SD standard deviation, GCS Glasgow Coma Scale, TBI traumatic brain injury *Continuous drugs used: norepinephrine, dopamine, dobutamine, propofol, clonidine, sodium nitroprusside, labetalol, alteplase, heparin, isosorbide dinitrate, nitroglycerin, atosiban

been interrupted for the duration of transfer, allowing paramedics to take care of the patient from this category without EP.

HEMS should be used for IFT if medical competences that exceed GA competences are needed or may be needed during transfer, or if speed is needed and the estimated time from call to arrival at the destination is faster with a helicopter. In the setting described, the hospital physician in charge of the patient performs this triage, but they are often not aware of paramedic competences and do not have the information on GA availability. Ideally, a dispatch centre should decide whether to allow HEMS transfers or not based on the need of HEMS for primary missions, the patient's condition, the suspected pathology and time gained by using HEMS for IFT. This would require advanced medical competences within the dispatch centre; it may also allow the treatment to be simplified wherever possible, to enable the GA to take care of the patient.

In the future, to better understand the use of HEMS for IFT and thus be able to propose new guidelines, it should be mandatory to prospectively document the reason why physicians choose HEMS instead of GA, in particular if it is a matter of speed or level of care. It should also be mandatory to evaluate whether ongoing continuous treatment can be stopped briefly or not. The dispatch centre should be capable of deciding whether to use HEMS for IFT rather than in-hospital physicians; all of those measures may contribute to a reduction in the over-use of HEMS for IFT.

The results point out that there are numerous signs of over-triage in this case-mix, regarding either the flight distances, clinical categories, medical procedures performed during flight, and diagnosis of patients. However, we lack two critical pieces of information to fully circumscribe the issue: the reason why HEMS is requested (speed? Medical competences?) and the estimate time 
Table 2 Patients' 48 h outcome according to the type of care provided

\begin{tabular}{|c|c|c|c|c|}
\hline \multirow[b]{2}{*}{ Outcome at $48 \mathrm{~h}(=\mathrm{n})$} & \multirow[b]{2}{*}{ Total $(n=979)$} & \multicolumn{3}{|l|}{ Type of care } \\
\hline & & $\begin{array}{l}\text { Simple clinical examination } \\
(n=324)(33.1 \%)\end{array}$ & $\begin{array}{l}\text { Emergency treatment } \\
(n=615)(62.8 \%)\end{array}$ & $\begin{array}{l}\text { Resuscitation or life-saving measures } \\
(n=40)(4.1 \%)\end{array}$ \\
\hline Hospitalized in intensive care unit & $425(43.4)$ & $75(7.7)$ & $325(33.2)$ & $25(2.6)$ \\
\hline Hospitalized in intermediate care unit & $196(20)$ & $96(9.8)$ & $96(9.8)$ & $4(0.4)$ \\
\hline Hospitalized in ward division & $181(18.5)$ & $70(7.2)$ & $108(11.0)$ & $3(0.3)$ \\
\hline Transfer to another institution & $88(9)$ & $42(4.3)$ & $45(4.6)$ & $1(0.1)$ \\
\hline Hospitalized and returned home & $44(4.5)$ & $34(3.5)$ & $10(1.0)$ & - \\
\hline Not hospitalized, discharged & $9(0.9)$ & $4(0.4)$ & $5(0.5)$ & - \\
\hline Died: 0-1 h (after admission) & $3(0.3)$ & $1(0.1)$ & - & $2(0.2)$ \\
\hline Died: $1-6 \mathrm{~h}$ & $3(0.3)$ & - & $3(0.3)$ & - \\
\hline Died: 6-24 h & $19(1.9)$ & - & $14(1.4)$ & $5(0.5)$ \\
\hline Died: 24-48 h & $11(1.1)$ & $2(0.2)$ & $9(0.9)$ & - \\
\hline
\end{tabular}

Table 3 Operational characteristics

\begin{tabular}{|c|c|c|}
\hline & HEMS & Road (estimated) \\
\hline Total missions, $\mathrm{n}$ & 979 & 979 \\
\hline Median distance (km) (IQR) & $35.4(22.5--40.2)$ & $47.7(30.5-71.1)$ \\
\hline$<30 \mathrm{~km}, \mathrm{n}(\%)^{\mathrm{a}}$ & $342(34.9)$ & $241(24.6)$ \\
\hline$\geq 100 \mathrm{~km}, \mathrm{n}(\%)^{n}$ & $37(3.8)$ & $70(7.1)$ \\
\hline Median duration (min) (IQR) & $12(10-15)$ & \\
\hline \multicolumn{3}{|l|}{ Flow of transfers \& clinical classification } \\
\hline University to university & $32(3.3 \%)$ & \\
\hline Simple clinical examination & $6(0.6)$ & \\
\hline Emergency treatment & $26(2.7)$ & \\
\hline Resuscitation or life-saving measures & $0(0)$ & \\
\hline Regional to regional & $36(3.7 \%)$ & \\
\hline Simple clinical examination & $14(1.4)$ & \\
\hline Emergency treatment & $21(2.1)$ & \\
\hline Resuscitation or life-saving measures & $1(0.1)$ & \\
\hline University to regional & 139 (14.2\%) & \\
\hline Simple clinical examination & $39(4.0)$ & \\
\hline Emergency treatment & $98(10.0)$ & \\
\hline Resuscitation or life-saving measures & $2(0.2)$ & \\
\hline Regional to university & $772(78.8 \%)$ & \\
\hline Simple clinical examination & $265(27.1)$ & \\
\hline Emergency treatment & $470(48.0)$ & \\
\hline Resuscitation or life-saving measures & $37(3.8)$ & \\
\hline Night mission 7 pm-7 am & $361(36.9 \%)$ & \\
\hline
\end{tabular}


saved using HEMS versus GA for each IFT, taking into account the time from the alarm and the fact that an ambulance may already be at the hospital.

There will always be a certain amount of over-triage in the use of HEMS for transfer and we should accept it. The question, as always, is how much is too much?

\section{Limitations.}

This is a monocentric and retrospective study. The data available could not define whether primary missions needing HEMS had to go by ground because of transfer activity with the helicopter. The reason why physicians required HEMS instead of a GA for transfer is not known, as it is not documented in hospital or prehospital charts. The category used to describe the treatment received during flight is not a validated standard. Air and ground distances were estimated using Google Maps ${ }^{\circ}$. The elapsed time between HEMS activation and arrival at the patient's bedside was not described, as some transfers were 'scheduled', meaning that the crew was asked to take off within a specific delay (30$90 \mathrm{~min}$ ). Only the duration of transport by HEMS was measured, rather than the entire process from the alarm to the arrival of HEMS at the receiving facility. No direct comparison was made with a GA; therefore, we cannot assess whether using HEMS for those transfers was quicker than if they had been performed by GA. This study did not intend to measure under-triage, as this would have required the operational characteristics of ground IFTs.

This study took place in a specific setting (geography, paramedics' autonomy, absence of EPs in GAs), and may not be applicable elsewhere.

\section{Conclusions}

The case-mix of IFTs by HEMS analysed presents a high severity. There are many signs in favour of over-triage. We propose indicators to help to determine whether HEMS is the most appropriate to perform the transfer regarding patient condition, geography, and medical competences available on-board GA; this may reduce over-triage.

\section{Abbreviations \\ EMS: Emergency medical service; EP: emergency physician; GA: Ground ambulance; HEMS: Helicopter emergency medical service; ICU: Intensive care unit; IFT: Inter-facility transfer; ISS: Injury severity score; STEMI: ST-elevation myocardial infarction}

\section{Competing interests.}

The authors declare that they have no competing interests.

\section{Availability of data and materials.}

The data generated or analysed during the current study are available from the corresponding author on reasonable request.

\section{Authors' contributions.}

DDR generated, analysed and interpreted the data, and was a major contributor in writing the manuscript. FD analysed and interpreted the transfer data, and was a major contributor in writing the manuscript. PNC, EA and MP critically revised the manuscript for important intellectual content, and approved the final version to be published. All authors read and approved the final manuscript.

\section{Ethics approval and consent to participate.}

This study was authorized by the Lausanne University Ethics Committee for Human Research and by the state's Public Health Service (CER-VD 2016-00995). As it is a retrospective study, without intervention, from a de-identified data base, no consent to participate was required the Ethics Committee, even for children.

\section{Publisher's Note}

Springer Nature remains neutral with regard to jurisdictional claims in published maps and institutional affiliations.

\section{Author details}

${ }^{1}$ Medical Student, Faculty of Medicine, University of Lausanne, Lausanne, Switzerland. ${ }^{2}$ Emergency Department, Lausanne University Hospital (CHUV), Bugnon 46, 1011 Lausanne, Switzerland. ${ }^{3}$ Department of Anaesthesia, Lausanne University Hospital, Lausanne, Switzerland.

Received: 12 December 2017 Accepted: 2 May 2018

Published online: 16 May 2018

\section{References}

1. Boyd CR, Corse KM, Campbell RC. Emergency inter-hospital transport of the major trauma patient: air versus ground. J Trauma. 1989 Jun;29(6):789-94.

2. Arfken CL, Shapiro MJ, Bessey PQ, Littenberg B. Effectiveness of helicopter versus ground ambulance services for inter-facility transport. J Trauma. 1998 Oct; 45(4):785-90.

3. Hill AD, Fowler RA, Nathens AB. Impact of inter-hospital transfer on outcomes for trauma patients: a systematic review. J Trauma Inj Infect Crit Care. 2011 Dec;71(6):1885-901.

4. Ryb GE, Dischinger P, Cooper C, Kufera JA. Does helicopter transport improve outcomes independently of emergency medical system time? J Trauma Acute Care Surg. 2013 Jan;74(1):149-56.

5. Karanicolas PJ, Bhatia P, Williamson J, Malthaner RA, Parry NG, Girotti MJ, et al. The fastest route between two points is not always a straight line: an analysis of air and land transfer of non-penetrating trauma patients. J Trauma Inj Infect Crit Care. 2006 Aug:61(2):396-403.

6. Koval KJ. Are patients being transferred to level-I trauma centres for reasons other than medical necessity? J Bone Jt Surg Am. 2006 Oct 1;88(10):2124

7. Galvagno Jr SM, Sikorski R, Hirshon JM, Floccare D, Stephens C, Beecher D, et al. Helicopter emergency medical services for adults with major trauma. In: Cochrane Database of Systematic Reviews [Internet]. John Wiley \& Sons, Ltd; 2015 [cited 2016 Mar 1]. Available from: http://onlinelibrary.wiley.com/ doi/10.1002/14651858.CD009228.pub3/full

8. Foster NA, Elfenbein DM, Kelley W Jr, Brown CR, Foley C, Scarborough JE, et al. Comparison of helicopter versus ground transport for the inter-facility transport of isolated spinal injury. Spine J. 2014 Jul 1;14(7):1147-54.

9. Stewart K, Garwe T, Bhandari N, Danford B, Albrecht R. Factors associated with the use of helicopter inter-facility transport of trauma patients to tertiary trauma centres within an organised rural trauma system. Prehospital Emerg Care Off J Natl Assoc EMS Physicians Natl Assoc State EMS Dir. 2016; 20(5):601-8.

10. Stewart KE, Cowan LD, Thompson DM, Sacra JC. Factors at the scene of injury associated with air versus ground transport to definitive care in a state with a large rural population. Prehosp Emerg Care. 2011 Mar 9; 15(2):193-202.

11. Brown JB, Stassen NA, Bankey PE, Sangosanya AT, Cheng JD, Gestring ML. Helicopters improve survival in seriously injured patients requiring interfacility transfer for definitive care. J Trauma Inj Infect Crit Care. 2011 Feb; 70(2):310-4

12. Moylan JA, Fitzpatrick KT, Beyer AJ, Georgiade GS. Factors improving survival in multisystem trauma patients. Ann Surg. 1988 Jun;207(6):679-85.

13. Campbell R, Corse K, Boyd C. Impact of inter-hospital air transport on mortality in a rural trauma system. Ann Emerg Med. 1989 Apr;18(4):474. 
14. Carron P-N, Taffe P, Ribordy V, Schoettker P, Fishman D, Yersin B. Accuracy of pre-hospital triage of trauma patients by emergency physicians: a retrospective study in western Switzerland. Eur J Emerg Med. 2011 Apr; 18(2):86-93.

15. Kristiansen T, Lossius HM, Søreide K, Steen PA, Gaarder C, Næss PA. Patients Referred to a Norwegian Trauma Centre: effect of transfer distance on injury patterns, use of resources and outcomes. J Trauma Manag Outcomes [Internet]. 2011 Dec [cited 2017 Sep 3];5(1). Available from: https://doi.org/ 10.1186/1752-2897-5-9.

16. Kim OH, Roh Y-I, Kim H-I, Cha YS, Cha K-C, Kim H, et al. Reduced mortality in severely injured patients using hospital-based helicopter emergency medical services in inter-hospital transport. J Korean Med Sci. 2017;32(7):1187.

17. Svenson JE, O'Connor JE, Lindsay MB. Is air transport faster? A comparison of air versus ground transport times for inter-facility transfers in a regional referral system. Air Med J. 2006 Jul;25(4):170-2.

Ready to submit your research? Choose BMC and benefit from:

- fast, convenient online submission

- thorough peer review by experienced researchers in your field

- rapid publication on acceptance

- support for research data, including large and complex data types

- gold Open Access which fosters wider collaboration and increased citations

- maximum visibility for your research: over $100 \mathrm{M}$ website views per year

At BMC, research is always in progress.

Learn more biomedcentral.com/submissions 